\title{
De Novo Intracranial Aneurysms Detected on Imaging Follow-Up of Coiled Aneurysms in a Korean Population
}

\author{
Eung Koo Yeon, $M D^{1}$, Young Dae Cho, MD, PhD², Dong Hyun Yoo, $\mathrm{MD}^{2}$, Su Hwan Lee, $\mathrm{MD}^{3}$, \\ Hyun-Seung Kang, MD, $\mathrm{PhD}^{4}$, Won Sang Cho, MD ${ }^{4}$, Jeong Eun Kim, MD, PhD ${ }^{4}$, Moon Hee Han, MD, PhD
}

${ }^{1}$ Department of Radiology, KyungHee University Medical Center, KyungHee University College of Medicine, Seoul, Korea; Departments of ${ }^{2}$ Radiology and ${ }^{4}$ Neurosurgery, Seoul National University Hospital, Seoul National University College of Medicine, Seoul, Korea; ${ }^{3}$ Department of Neurosurgery, Dongguk University Ilsan Hospital, Dongguk University College of Medicine, Goyang, Korea; ${ }^{5}$ Department of Radiology, Veterans Health Service Medical Center, Seoul, Korea

Objective: Coiled aneurysms are known to recanalize over time, making follow-up evaluations mandatory. Although de novo intracranial aneurysms (DNIAs) are occasionally detected during routine patient monitoring, such events have not been thoroughly investigated to date. Herein, we generated estimates of DNIA development during long-term observation of coiled cerebral aneurysms, focusing on incidence and the risk factors involved.

Materials and Methods: In total, 773 patients undergoing coil embolization of intracranial aneurysms between 2008 and 2010 were reviewed retrospectively. Their medical records and radiologic data accrued over the extended period (mean, 52.7 \pm 29.7 months) were analyzed. For the detection of DNIA, follow-up magnetic resonance angiography and/or conventional angiography were used. The incidence of DNIAs and related risk factors were analyzed using Cox proportional hazards regression and Kaplan-Meier product-limit estimator.

Results: In 19 (2.5\%) of the 773 patients with coiled aneurysms, DNIAs (0.56\% per patient-year) developed during continued long-term monitoring (3395.3 patient-years). Of these, 9 DNIAs (47.4\%) were detected within 60 months, with $10(52.6 \%)$ emerging thereafter. The most common site involved was the posterior communicating artery $(n=6)$, followed by the middle cerebral artery $(n=5)$ and the basilar top $(n=4)$. Multivariate analysis indicated that younger age $(<50$ years) (hazard ratio $[\mathrm{HR}]=1.045 ; p=0.010)$ and recanalization of coiled aneurysms $(\mathrm{HR}=2.560 ; p=0.047)$ were significant factors in DNIA formation, whereas female sex, smoking, and hypertension fell short of statistical significance. Cumulative survival rates without DNIA were significantly higher in older subjects ( $>60$ years; $p<0.001$ ) and in the absence of post-coiling aneurysm recurrence $(p=0.006)$.

Conclusion: In most patients with coiled aneurysms, development of DNIAs during long-term monitoring is rare. However, younger patients ( $<50$ years) or patients with recurring aneurysms appear to be predisposed to DNIAs.

Keywords: Aneurysm; Follow up; De novo; Coil embolization

\section{INTRODUCTION}

Intracranial aneurysms (IAs) leading to subarachnoid

Received December 28, 2018; accepted after revision June 12, 2019.

Corresponding author: Young Dae Cho, MD, PhD, Department of Radiology, Seoul National University College of Medicine, 101 Daehak-ro, Jongno-gu, Seoul 03080, Korea.

- Tel: (822) 2072-2987 - Fax: (822) 743-6385

- E-mail: aronnn@naver.com

This is an 0pen Access article distributed under the terms of the Creative Commons Attribution Non-Commercial License (https://creativecommons.org/licenses/by-nc/4.0) which permits unrestricted non-commercial use, distribution, and reproduction in any medium, provided the original work is properly cited. hemorrhage $(\mathrm{SAH})$ are significantly linked with patient mortality and morbidity. Despite advancements in managing such events, the overall case fatality rate remains high (1). For this reason, many patients whose IAs remain unruptured are candidates for preventive surgical or endovascular intervention. Currently, IAs are found in approximately 3\% of the general population throughout their lifetimes (2).

De novo intracranial aneurysms (DNIAs) are newly identified aneurysms arising from vessels previously documented as normal in imaging studies (3). Although rare, the potential development of DNIAs after endovascular embolization is nevertheless a matter of concern. Such lesions are typically detected during long-term follow-up 
imaging in patients with IAs. There have been some prior studies regarding DNIAs in this setting (4-9), offering a broad range of incidence (0.3-4.4\% per patient-year) due to differences in study population volumes, observation periods, and follow-up protocols (3-12). Reported risk factors for DNIA formation, such as age, female sex, hypertension (HTN), and smoking history, have also been inconsistent $(3,5-10,12-18)$, and there is little guidance regarding the frequency and interval of scheduled imaging after endovascular treatment. We therefore generated estimates of DNIA development during long-term observation of coiled cerebral aneurysms, determining DNIA incidence rates and related risk factors.

\section{MATERIALS AND METHODS}

\section{Study Population}

A total of 1035 consecutive coil embolization procedures performed at a single institution between January 2008 and December 2010 were assessed for this retrospective review. Non-saccular aneurysms $(n=70)$ were excluded, leaving 965 saccular aneurysms eligible for the study. The endpoint was DNIA development during extended follow-up of coiled aneurysms. Sixty-six lesions with $<6$-month follow-up were further excluded. Ultimately, 773 patients with 899 aneurysms were investigated. During the same period, 133 different patients with 148 aneurysms were treated with surgical clipping. However, they could not be included in this study because regular imaging follow-up was not recommended according to our institutional protocol for patients who underwent clipping. This study was approved by our Institutional Review Board, which waived the requirement for written informed consent.

Information regarding multiple patient variables, including sex, age, comorbidities (HTN, hyperlipidemia, diabetes mellitus), smoking, alcohol intake, and clinical presentation (unruptured intracranial aneurysm vs. subarachnoid hemorrhage $[\mathrm{SAH}]$ ), were retrieved from medical records. Angiographic data on coiled aneurysms were also collected, namely, size of the aneurysm (overall and neck dimensions), location (anterior vs. posterior circulation), nature of the aneurysm (side-wall vs. bifurcation type), aneurysm status (initial vs. second embolization), and multiplicity of lesions. In patients with multiple coiled aneurysms, data of the largest aneurysm were used for analysis. Procedural variables for stent usage were also reviewed.

\section{Study Evaluation}

Follow-up radiologic examinations of patients with coiled aneurysms were performed at $6,12,24$, and 36 months post-procedure with time-of-flight magnetic resonance angiography (TOF-MRA) using three-dimensional reconstruction and source images (19). If magnetic resonance angiography (MRA) was not feasible or if recanalization was suspected by MRA, conventional angiography was performed to determine the need for further treatment. Thereafter, examinations at intervals of 2-3 years were suggested, particularly in younger patients and in lesions involving SAH presentation, other untreated aneurysms, retreatment, or recanalization during followup. Anatomic outcomes of coiled aneurysms were gauged as complete occlusion or recanalization (minor or major) by using the Raymond-Roy criteria for occlusion in coiled aneurysms (20). Repeat embolization was recommended for patients showing major recanalization.

DNIA was defined as an aneurysm $>1.5 \mathrm{~mm}$ in size arising from a parent vessel previously normal in imaging studies, either MRA or conventional angiography (3). The full array of follow-up diagnostic examinations was randomly ordered, allowing two experienced neurointerventionists (10 years and 15 years) to independently review follow-up MRAs (maximum intensity projection images and source images) and conventional angiographic studies. Each reviewer was blinded to pertinent clinical and radiologic information. In the event of disagreement, a consensus was established by a third interventional neuroradiologist $(>25$ years of experience).

\section{Statistical Analysis}

Interobserver agreement for the evaluation of TOF-MRA (and/or conventional angiography) findings was analyzed by means of weighted kappa statistics. Continuous data were expressed as mean \pm standard deviation. Chi-squared and Fisher's exact tests or unpaired $t$ test were used to assess categorical or continuous variables, respectively. Univariate analysis of parameters impacting DNIA formation after coiling relied on Cox proportional hazards regression by using designated outcomes $(p<0.20)$ in a multivariable model to determine risk factors. The average annual risk of DNIA in patients with coiled aneurysms was calculated as the total DNIAs divided by the patient-year total for follow-up periods. Kaplan-Meier product-limit estimator and generalized Wilcoxon tests were applied to compute the cumulative survival rate by risk factors in the absence 
of DNIA. Statistical significance was set at $p<0.05$, employing standard software (SPSS v19; SPSS Inc., Chicago, IL, USA) for all purposes.

\section{RESULTS}

\section{Clinical and Radiologic Characteristics in the Study Population}

We monitored the coiled aneurysms of 773 patients for extended periods (mean, $52.7 \pm 29.7$ months; range, 6-126 months). Patients were predominantly female (525/773, $67.9 \%$ ) and the mean age of the subjects was $57.9 \pm 10.7$ years. A majority of patients $(491 / 773,63.5 \%)$ had HTN, but only 141 (18.2\%) were smokers. Anterior (713/773, $92.2 \%)$ rather than posterior $(20 / 773,7.8 \%)$ circulation was primarily involved, and side-wall aneurysms (420/773, $54.3 \%$ ) were slightly more common than bifurcation aneurysms (353/773, 45.7\%). In 140 patients, the aneurysms were accompanied with SAH. Moreover, 225 patients had multiple aneurysms, and the aneurysms of 53 patients (6.9\%) were retreated lesions (second treatments). Mean estimated aneurysm size was $5.6 \pm 3.0 \mathrm{~mm} ; 406$ aneurysms $(52.5 \%)$ were $\leq 5 \mathrm{~mm}$ and $51(6.6 \%)$ were $>10$ $\mathrm{mm}$ in size. Mean neck size was $3.7 \pm 1.7 \mathrm{~mm}$, with 223 aneurysms (28.8\%) qualifying as wide-necked lesions ( $>4$ $\mathrm{mm}$ ). During the procedure, stents were deployed in 210 patients. During follow-up evaluations, 198 patients showed recanalization of coiled aneurysms (minor, 89; major, 109). Patient characteristics are detailed in Table 1.

\section{Characteristics for DNIA Formation}

Of the 773 patients with coiled aneurysms under observation for $>6$ months, DNIAs were confirmed in 19 (2.5\%) during continued monitoring (3395.3 patientyears); 9 (47.4\%) DNIAs surfaced within 60 months and 10 $(52.6 \%)$ appeared thereafter. Within this time frame, interobserver agreement in assessing DNIA was excellent $(\kappa=$ 0.875; range, $0.820-0.930)$. The characteristics of DNIAs detected are summarized in Table 2. Mean size of DNIAs was $3.3 \pm 1.6 \mathrm{~mm}$ (range, $1.5-8.7 \mathrm{~mm}$; median, $3.0 \mathrm{~mm}$ ). In one patient, the DNIA was identified in the midst of SAH presentation, whereas the remaining 18 aneurysms were documented during regular follow-up and were unruptured. The posterior communicating artery $(P c o m A ; n=6)$ was the most common site of DNIAs, followed by the middle cerebral artery $(n=5)$, basilar top $(n=4)$, anterior communicating artery $(n=2)$, and distal segments of the anterior cerebral or internal carotid artery ( $\mathrm{n}=1$, each). In two patients, DNIAs developed adjacent to coiled aneurysms (Fig. 1), and one of the DNIAs emerged from the infundibulum of PcomA origin. Of the 19 DNIAs identified, 9 aneurysms (including one accompanied with $\mathrm{SAH}$ ) $\geq 3 \mathrm{~mm}$ in size were treated (endovascular coiling, 8; surgical clipping, 1). Further follow-up was recommended for the remaining 10 aneurysms, which were smaller $(<3 \mathrm{~mm})$.

\section{Risk Factors for DNIA Formation}

In univariate analysis, patient age, retreatment, and recanalization during follow-up differed significantly between patients without $(n=754)$ and with $(n=19)$ DNIAs (Table 1). Binary logistic regression analysis indicated that younger age (hazard ratio $[\mathrm{HR}]=1.045$, 95\% confidence interval [CI]: $1.010-1.081 ; p=0.010)$ and recanalization of coiled aneurysms (HR $=2.560,95 \%$ CI: $1.012-6.481 ; p=0.047$ ) were independently correlated with the development of DNIAs in patients with coiled aneurysm (Table 3).

During follow-up, DNIAs were detected in a mean of $61.5 \pm 22.0$ months (median, 62 months; range, 33-102 months). The overall DNIA development rate was $0.56 \%$ per patient-year. Annual rates of DNIA formation for specific risk factors were estimated as follows: 1$)$ age ( $\leq 50$ years, $1.51 \%$ per patient-year; $>50$ and $\leq 60$ years, $0.35 \%$ per patient-year; $>60$ years, $0.14 \%$ per patient-year) and 2) recanalization (complete occlusion, $0.31 \%$ per patientyear; recanalization, $1.05 \%$ per patient-year). KaplanMeier rate estimates of cumulative survival without DNIA are presented in Figure 2. The overall survival rate was $98.1 \%$, but 84 -month estimates differed by age ( $\leq 50$ years, $93.5 \%$; $>50$ and $\leq 60$ years, $98.4 \%$; $>60$ years, $99.4 \%$ ) and recanalization (complete occlusion, $99.0 \%$; recanalization, $94.4 \%)$. Cumulative survival rates without DNIA reached significance for age $(p<0.001)$ and recanalization $(p=$ $0.006)$ via generalized Wilcoxon analysis.

\section{DISCUSSION}

In the present study, we found that DNIAs developed in $19(2.5 \%)$ of 773 patients with coiled aneurysms in followup imaging, yielding a cumulative estimated incidence of $0.56 \%$ per patient-year. This result was slightly higher than the outcomes of a prior systematic review (incidence, $2 \%$; incidence density, $0.3 \%$ per patient-year) (3). The incidence of DNIA formation in the surgical clipping group was about 
Table 1. Demographic and Angiographic Characteristics of Patients with Prior Coiled Aneurysms $(\mathrm{n}=773)$

\begin{tabular}{|c|c|c|c|}
\hline Variables & Patients without DNIA $(n=754)$ & Patients with DNIA $(n=19)$ & $P$ \\
\hline \multicolumn{4}{|l|}{ Patient variables } \\
\hline Female & 511 & 14 & 0.819 \\
\hline Age (years) & $58.1 \pm 10.6$ & $49.2 \pm 8.8$ & 0.006 \\
\hline$\leq 50$ & 171 & 13 & \\
\hline $50<$ and $\leq 60$ & 246 & 4 & \\
\hline$>60$ & 337 & 2 & \\
\hline Hypertension & 481 & 10 & 0.409 \\
\hline Diabetes & 82 & 1 & 0.435 \\
\hline Hyperlipidemia & 319 & 7 & 0.705 \\
\hline Alcohol & 233 & 7 & 0.552 \\
\hline Smoking & 138 & 3 & 0.943 \\
\hline Follow-up period (months) & $52.5 \pm 29.9$ & $61.5 \pm 22.0$ & \\
\hline \multicolumn{4}{|l|}{ Coiled aneurysm variables } \\
\hline Multiplicity & & & 0.901 \\
\hline Single & 534 & 14 & \\
\hline Multiple & 220 & 5 & \\
\hline Presentation & & & 0.177 \\
\hline Ruptured & 133 & 7 & \\
\hline Unruptured & 621 & 12 & \\
\hline Location & & & 0.778 \\
\hline Anterior & 696 & 17 & \\
\hline Posterior & 58 & 2 & \\
\hline Status & & & 0.023 \\
\hline Initial & 706 & 14 & \\
\hline Retreatment* & 48 & 5 & \\
\hline Type & & & 0.349 \\
\hline Side-wall & 405 & 15 & \\
\hline Bifurcation & 349 & 4 & \\
\hline Maximum size $(\mathrm{mm})$ & $5.6 \pm 3.0$ & $6.0 \pm 3.1$ & 0.983 \\
\hline$\leq 5$ & 399 & 7 & \\
\hline $5<$ and $\leq 10$ & 305 & 11 & \\
\hline$>10$ & 50 & 1 & \\
\hline Neck size $(\mathrm{mm})$ & $3.7 \pm 1.8$ & $3.6 \pm 1.5$ & 0.398 \\
\hline$\leq 4$ & 537 & 13 & \\
\hline$>4$ & 217 & 6 & \\
\hline Stent usage & 205 & 5 & \\
\hline Recanalization & & & 0.010 \\
\hline Complete occlusion & 568 & 7 & \\
\hline Recanalization & 186 & 12 & \\
\hline Minor & 87 & 2 & \\
\hline Major & 99 & 10 & \\
\hline
\end{tabular}

*Retreatment indicates second embolization. DNIA = de novo intracranial aneurysm

$2.6-3.3 \%(0.3-0.6 \%$ per patient-year), which was not significantly different from the results of our study $(16,17)$. DNIA may be a phenotype of metachronous multiple IAs, the incidence of which is variably reported to be $15-30 \%$ (21). According to a systematic review and meta-analysis, the risk factors for multiple IAs are as follows: female sex, smoking, HTN, older patient age, and DNIA formation (22). The precise mechanisms of DNIA formation are as yet unclear, but it is likely that multiple factors are involved. According to several relevant reports, the risk factors associated with DNIA formation are female sex, younger age, HTN, past history of SAH, and smoking (5, 7, 13, 15, 18, 23-30), 
Table 2. Characteristics of DNIAs ( $n=19)$

\begin{tabular}{|c|c|}
\hline Variables & No. $(\%)$ \\
\hline Detection period (months) & 33-146 (median 62) \\
\hline \multicolumn{2}{|l|}{ Locations } \\
\hline Anterior circulation & $15(78.9)$ \\
\hline PcomA & 6 \\
\hline MCA & 5 \\
\hline AcomA & 2 \\
\hline ACA & 1 \\
\hline ICA & 1 \\
\hline Posterior circulation & $4(21.1)$ \\
\hline Basilar top & 4 \\
\hline \multicolumn{2}{|l|}{ Aneurysm size (mm) } \\
\hline$\leq 3$ & $10(52.6)$ \\
\hline$>3$ & $9(47.3)$ \\
\hline \multicolumn{2}{|l|}{ Presentation } \\
\hline Unruptured aneurysms & $18(94.7)$ \\
\hline Subarachnoid hemorrhage & $1(5.3)$ \\
\hline \multicolumn{2}{|l|}{ Relation of coiled aneurysm } \\
\hline Same site & $2(10.6)$ \\
\hline Other site & $17(89.4)$ \\
\hline \multicolumn{2}{|l|}{ Treatment } \\
\hline Observation \& follow-up & $10(52.6)$ \\
\hline Coiling & $8(42.1)$ \\
\hline Clipping & $1(5.3)$ \\
\hline
\end{tabular}

$\mathrm{ACA}=$ anterior cerebral artery, AcomA = anterior communicating artery, ICA = internal carotid artery, MCA = middle cerebral artery, Pcom $A=$ posterior communicating artery

similar to the factors associated with multiple IAs. These findings suggest that DNIA formation may be influenced by the systemic profiles of patients rather than being affected solely by local forces. However, other researchers partially refute this, claiming that female sex, HTN, and smoking are not culpable, as we also have concluded $(12,16,28,31$, 32 ). Therefore, the factors contributing to DNIA formation are still controversial.

In the present study, we identified two significant risk factors for DNIA formation among the various clinical and anatomic variables analyzed. Younger age at initial IA diagnosis proved to be an independent risk factor for DNIA formation in binary logistic regression analysis $(H R=1.045$, $95 \%$ CI, $1.010-1.081 ; p=0.010$ ), particularly in patients aged $\leq 50$ years. In younger patients, the annual DNIA formation rate was 10 -fold greater, relative to patients > 60 years ( $1.51 \%$ vs. $0.14 \%$ per patient-year); and compared with elder patients, the younger subset displayed a significantly lower cumulative survival rate without DNIA $(p<0.001)$. These findings are perhaps related to the propensity of IA development in the general population.
The overall prevalence of IA in a meta-analysis was estimated to be $3.2 \%$ in a population without comorbidity (2), at a mean age of 50 years. In addition, the prevalence of IA was higher in adults aged $>60$ years, in comparison with younger adults. Therefore, it seems that the majority of the aneurysms develop in patients aged $<60$ years. In our series, DNIAs were detected in only two $(0.6 \%)$ of 339 patients $>60$ years old, which is remarkably lower than the rate of DNIA detection in patients aged $<50$ years (7.1\%). Hence, an extended monitoring beyond routine follow-up for coiled aneurysms may be more appropriate in younger patients, given their greater risk. Lindgren et al. (5) and Lecler et al. (33) have likewise reported correlations between younger age and the likelihood of DNIA formation.

The second risk factor for DNIA formation that we identified was recanalization of coiled aneurysms during follow-up (HR $=2.560,95 \%$ CI: $1.012-6.481 ; p=0.047$ ). In reviewing the current literature, no publications have yet addressed this proclivity. Consequently, we cannot readily offer any corroborating scientific evidence. However, it is plausible that arterial wall deformation and remodeling are common morphologic adaptations of both phenomena. Recanalization after coiling is related to aneurysmal growth to greater or lesser degrees $(34,35)$. Several experimental studies using computational fluid dynamics in a patientspecific vascular model have further indicated that the elasticity of the vascular wall may play a fundamental role in deformation of the arterial wall (36-38). A rigid (vs. elastic) wall serves to increase wall shear stress acting on the vascular wall in a pulsatile flow, potentially accentuating the hemodynamic impact on the endothelial cell, intima, and smooth muscle cell. Thus, vascular wall elasticity may be closely associated with arterial wall deformation, promoting both DNIA formation and growth of coiled aneurysms.

DNIAs rarely occur (about $2 \%$ incidence and $<1 \%$ per patient-year), and only one case involved SAH among the 19 DNIAs studied herein. Data from the International Subarachnoid Aneurysm Trial indicate an annual rupture rate of $0.04-0.06 \%$ due to DNIAs in patients with coiled aneurysms (39). Although the major concern for patients first diagnosed with IA is the risk of rupture, DNIA rupture seldom occurs. Therefore, serial imaging studies beyond a given routine protocol may not be cost-effective in most patients with coiled IAs. However, based on our study results, we suggest that careful follow-up with periodic scheduled imaging (e.g., intervals of 2-5 years after 3-year 

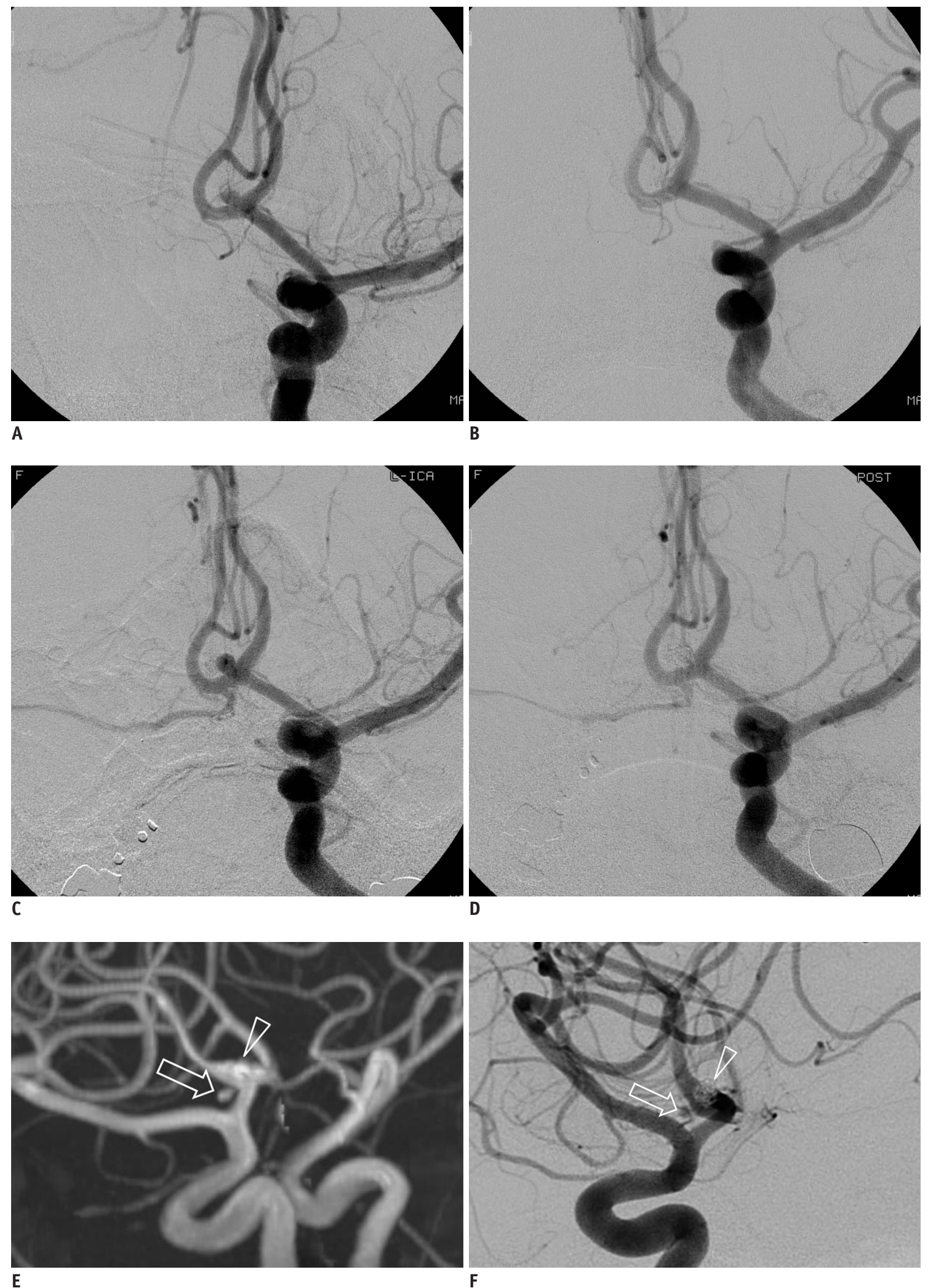

Fig. 1. Representative case of de novo aneurysm.

(A) Pre- and (B) post-embolization angiographic images of ruptured anterior communicating artery aneurysm. C. Conventional angiography with 6-month follow-up shows major recanalization of coiled aneurysm. D. Post-procedural angiography after additional coiling confirms successful occlusion of aneurysm. (E) Magnetic resonance and (F) conventional angiography in 60-month follow-up show de novo aneurysm (arrows) adjacent to coiled aneurysm (arrowheads). 
Table 3. Logistic Regression Model Assessing Risk of DNIAs in Patients with Prior Coiled Aneurysms

\begin{tabular}{lccc}
\hline \multicolumn{1}{c}{ Variables } & Hazard Ratio & $95 \%$ Confidence Interval & $P$ \\
\hline Age & 0.957 & $0.925-0.990$ & 0.010 \\
Ruptured aneurysm & 1.564 & $0.494-4.953$ & 0.447 \\
Second embolization & 2.565 & $0.912-7.215$ & 0.074 \\
Recanalization in follow-up & 2.560 & $1.012-6.481$ & 0.047 \\
\hline
\end{tabular}

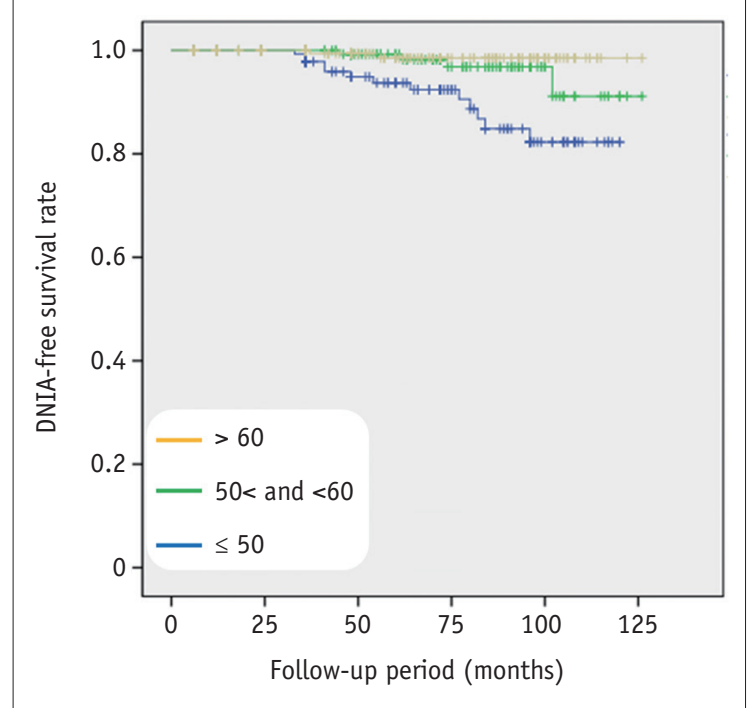

A

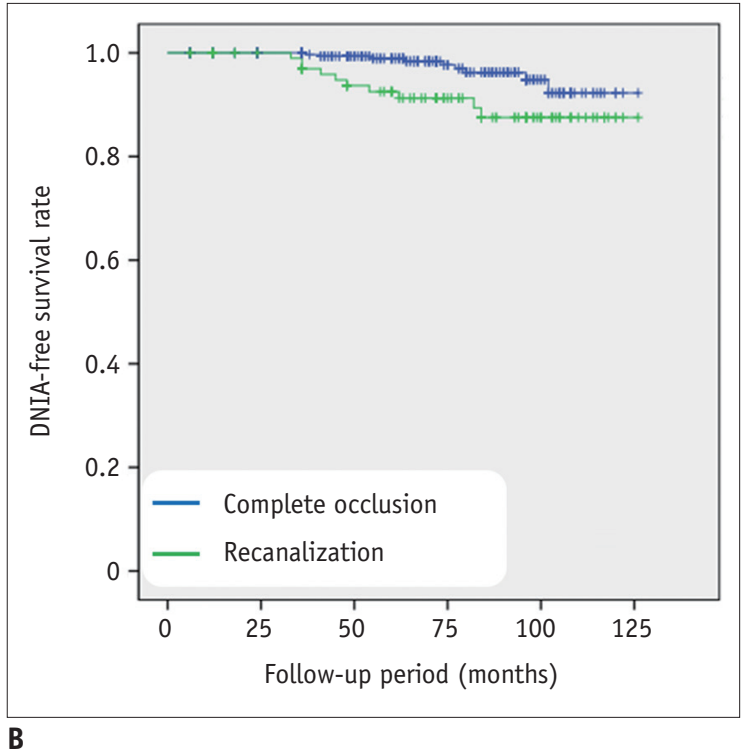

Fig. 2. Kaplan-Meier estimates of de novo aneurysm-free cumulative survival for (A) age at initial diagnosis of aneurysm and (B) recanalization of coiled aneurysm. DNIA $=$ de novo intracranial aneurysm

postembolization follow-up) may be reasonable as a longterm approach to exclude DNIAs in selected patients, particularly those aged $<50$ years at initial IA diagnosis or with recanalization of coiled aneurysms.

There were several limitations in this study, the first being the potential for selection bias in a retrospective review. The patients with aneurysms treated by surgical clipping were not included, inevitably due to a lack of the follow-up imaging data. Furthermore, the follow-up protocol was not well standardized within the designated population, with differing imaging modalities and variable exam intervals among individual subjects. Finally, due to the low probabilities of DNIA development, a small number of DNIAs observed in this study may have skewed our discovery of independent risk factors for DNIA formation. Further prospective studies examining a broader array of lesions are need for more conclusive support.

In conclusion, we have demonstrated that DNIAs developed in $2.5 \%$ of patients with coiled aneurysms and that the cumulative incidence was $0.56 \%$ per patient-year. Although the incidence of DNIA formation is rare, particular attention should be paid to patients aged $<50$ years at initial diagnosis of IA and those with recanalized coiled aneurysm after endovascular treatment.

\section{Conflicts of Interest}

The authors have no potential conflicts of interest to disclose.

\section{ORCID iDs}

Young Dae Cho

https://orcid.org/0000-0002-5293-2761

Eung Koo Yeon

https://orcid.org/0000-0001-7965-0118

Dong Hyun Yoo

https://orcid.org/0000-0003-1658-5341

Su Hwan Lee

https://orcid.org/0000-0002-9605-6476

Hyun-Seung Kang https://orcid.org/0000-0002-6957-1907

Won Sang Cho

https://orcid.org/0000-0002-3345-8718

Jeong Eun Kim

https://orcid.org/0000-0002-6927-3109 
Moon Hee Han

https://orcid.org/0000-0001-5476-3482

\section{REFERENCES}

1. Nieuwkamp DJ, Setz LE, Algra A, Linn FH, de Rooij NK, Rinkel GJ. Changes in case fatality of aneurysmal subarachnoid haemorrhage over time, according to age, sex, and region: a meta-analysis. Lancet Neurol 2009;8:635-642

2. Vlak MH, Algra A, Brandenburg R, Rinkel GJ. Prevalence of unruptured intracranial aneurysms, with emphasis on sex, age, comorbidity, country, and time period: a systematic review and meta-analysis. Lancet Neurol 2011;10:626-636

3. Giordan E, Lanzino G, Rangel-Castilla L, Murad MH, Brinjikji W. Risk of de novo aneurysm formation in patients with a prior diagnosis of ruptured or unruptured aneurysm: systematic review and meta-analysis. J Neurosurg 2018;131:1-11

4. Ferns SP, Sprengers ME, van Rooij WJ, van den Berg R, Velthuis $B K$, de Kort GA, et al. De novo aneurysm formation and growth of untreated aneurysms: a 5-year MRA followup in a large cohort of patients with coiled aneurysms and review of the literature. Stroke 2011;42:313-318

5. Lindgren AE, Räisänen S, Björkman J, Tattari $H$, Huttunen J, Huttunen $T$, et al. De novo aneurysm formation in carriers of saccular intracranial aneurysm disease in Eastern Finland. Stroke 2016;47:1213-1218

6. Rahmah NN, Horiuchi T, Kusano Y, Sasaki T, Hongo K. De novo aneurysm: case reports and literature review. Neurosurgery 2011;69:E761-E766; discussion E766-E767

7. Zali A, Khoshnood RJ, Zarghi A. De novo aneurysms in longterm follow-up computed tomographic angiography of patients with clipped intracranial aneurysms. World Neurosurg 2014;82:722-725

8. Kheireddin AS, Filatov YM, Belousova OB, Eliava SS, Sazonov IA, Kaftanov AN, et al. [De novo cerebral aneurysms]. Zh Vopr Neirokhir Im N N Burdenko 2015;79:75-81

9. Miller CA, Hill SA, Hunt WE. “De novo” aneurysms. A clinical review. Surg Neurol 1985;24:173-180

10. Sprengers ME, van Rooij WJ, Sluzewski M, Rinkel GJ, Velthuis BK, de Kort GA, et al. MR angiography follow-up 5 years after coiling: frequency of new aneurysms and enlargement of untreated aneurysms. AJNR Am J Neuroradiol 2009;30:303307

11. Kemp WJ 3rd, Fulkerson DH, Payner TD, Leipzig TJ, Horner TG, Palmer EL, et al. Risk of hemorrhage from de novo cerebral aneurysms. J Neurosurg 2013;118:58-62

12. Wang JY, Smith R, Ye X, Yang W, Caplan JM, Radvany MG, et al. Serial imaging surveillance for patients with a history of intracranial aneurysm: risk of de novo aneurysm formation. Neurosurgery 2015;77:32-42; discussion 42-43

13. Serrone JC, Tackla RD, Gozal YM, Hanseman DJ, Gogela SL, Vuong SM, et al. Aneurysm growth and de novo aneurysms during aneurysm surveillance. J Neurosurg 2016;125:1374-
1382

14. Juvela S, Poussa K, Porras M. Factors affecting formation and growth of intracranial aneurysms: a long-term follow-up study. Stroke 2001;32:485-491

15. Wermer MJ, van der Schaaf IC, Velthuis BK, Algra A, Buskens E, Rinkel GJ; ASTRA Study Group. Follow-up screening after subarachnoid haemorrhage: frequency and determinants of new aneurysms and enlargement of existing aneurysms. Brain 2005;128(Pt 10):2421-2429

16. van der Schaaf IC, Velthuis BK, Wermer MJ, Majoie C, Witkamp T, de Kort G, et al.; ASTRA Study Group. New detected aneurysms on follow-up screening in patients with previously clipped intracranial aneurysms: comparison with DSA or CTA at the time of SAH. Stroke 2005;36:1753-1758

17. Burkhardt JK, Chua MHJ, Weiss M, Do ASS, Winkler EA, Lawton MT. Risk of aneurysm residual regrowth, recurrence, and de novo aneurysm formation after microsurgical clip occlusion based on follow-up with catheter angiography. World Neurosurg 2017;106:74-84

18. Bruneau M, Rynkowski M, Smida-Rynkowska K, Brotchi J, De Witte 0, Lubicz B. Long-term follow-up survey reveals a high yield, up to $30 \%$ of patients presenting newly detected aneurysms more than 10 years after ruptured intracranial aneurysms clipping. Neurosurg Rev 2011;34:485-496

19. Cho YD, Kim KM, Lee WJ, Sohn CH, Kang HS, Kim JE, et al. Time-of-flight magnetic resonance angiography for followup of coil embolization with enterprise stent for intracranial aneurysm: usefulness of source images. Korean J Radiol 2014;15:161-168

20. Roy D, Milot G, Raymond J. Endovascular treatment of unruptured aneurysms. Stroke 2001;32:1998-2004

21. Takahashi S. Neurovascular imaging: MRI \& microangiography. London: Springer-Verlag, 2010:345-372

22. Jabbarli R, Dinger TF, Darkwah Oppong M, Pierscianek D, Dammann P, Wrede KH, et al. Risk factors for and clinical consequences of multiple intracranial aneurysms: a systematic review and meta-analysis. Stroke 2018;49:848-855

23. David CA, Vishteh AG, Spetzler RF, Lemole M, Lawton MT, Partovi S. Late angiographic follow-up review of surgically treated aneurysms. J Neurosurg 1999;91:396-401

24. Kim ST, Jeong HW, Jeong YG, In HS. Coiling as retreatment in intracranial aneurysm of de novo formation or regrowth: case report. Neurointervention 2013;8:46-51

25. Brown MA, Parish J, Guandique CF, Payner TD, Horner T, Leipzig $T$, et al. A long-term study of durability and risk factors for aneurysm recurrence after microsurgical clip ligation. J Neurosurg 2017;126:819-824

26. Bor AS, Rinkel GJ, van Norden J, Wermer MJ. Long-term, serial screening for intracranial aneurysms in individuals with a family history of aneurysmal subarachnoid haemorrhage: a cohort study. Lancet Neurol 2014;13:385-392

27. Miyazawa N, Akiyama I, Yamagata Z. Risk factors for growth of unruptured intracranial aneurysms: follow-up study by serial 0.5-T magnetic resonance angiography. Neurosurgery 
2006;58:1047-1053; discussion 1047-1053

28. Juvela S, Poussa K, Lehto H, Porras M. Natural history of unruptured intracranial aneurysms: a long-term follow-up study. Stroke 2013;44:2414-2421

29. Lai LT, Morgan MK, Patel NJ. Smoking increases the risk of de novo intracranial aneurysms. World Neurosurg 2014;82:e195-e201

30. Phan TG, Huston J 3rd, Brown RD Jr, Wiebers D0, Piepgras DG. Intracranial saccular aneurysm enlargement determined using serial magnetic resonance angiography. J Neurosurg 2002;97:1023-1028

31. Goksu E, Korkmaz E, Akyuz M, Ozgur 0, Sindel T, Tuncer R. The analysis of long-term follow-up screening in patients with surgically treated intracranial aneurysms. Turk Neurosurg 2015;25:404-409

32. Akyüz M, Tuncer R, Yilmaz S, Sindel T. Angiographic followup after surgical treatment of intracranial aneurysms. Acta Neurochir (Wien) 2004;146:245-250; discussion 250

33. Lecler A, Raymond J, Rodriguez-Régent C, Al Shareef F, Trystram D, Godon-Hardy S, et al. Intracranial aneurysms: recurrences more than 10 years after endovascular treatment-a prospective cohort study, systematic review, and meta-analysis. Radiology 2015;277:173-180

34. Cho YD, Jeon JP, Yoo DH, Cho WS, Kang HS, Kim JE, et al. Growth-related major recanalization of coiled aneurysms: incidence and risk factors. Neurosurgery 2018;82:185-191

35. Abdihalim M, Watanabe M, Chaudhry SA, Jagadeesan B, Suri MF, Qureshi AI. Are coil compaction and aneurysmal growth two distinct etiologies leading to recurrence following endovascular treatment of intracranial aneurysm? J Neuroimaging 2014;24:171-175

36. Xu L, Sugawara M, Tanaka G, Ohta M, Liu H, Yamaguchi R. Effect of elasticity on wall shear stress inside cerebral aneurysm at anterior cerebral artery. Technol Health Care 2016;24:349-357

37. Lee CJ, Zhang Y, Takao H, Murayama Y, Qian Y. A fluidstructure interaction study using patient-specific ruptured and unruptured aneurysm: the effect of aneurysm morphology, hypertension and elasticity. J Biomech 2013;46:2402-2410

38. Jahed M, Ghalichi F, Farhoudi M. Fluid-structure interaction of patient-specific Circle of Willis with aneurysm: investigation of hemodynamic parameters. Biomed Mater Eng 2018;29:357368

39. Molyneux AJ, Kerr RS, Birks J, Ramzi N, Yarnold J, Sneade $M$, et al.; ISAT Collaborators. Risk of recurrent subarachnoid haemorrhage, death, or dependence and standardised mortality ratios after clipping or coiling of an intracranial aneurysm in the International Subarachnoid Aneurysm Trial (ISAT): long-term follow-up. Lancet Neurol 2009;8:427-433 